\title{
Effects of earthworm (Metaphire guillelmi) addition on soil aggregate organic carbon content and clover root characteristics
}

\author{
Li Ma ${ }^{1}$, Mingan $\mathrm{Shao}^{2}$, and Jing $\mathrm{Li}^{1}$ \\ ${ }^{1}$ Key Lab of Disaster Monitoring and Mechanism Simulating of Shaanxi Province \\ ${ }^{2}$ Institute of Geographic Sciences and Natural Resources Research Chinese Academy of \\ Sciences
}

February 9, 2022

\begin{abstract}
Earthworms can variously affect soil properties and resource availability by feeding, burrowing, and casting activities. Figuring out the relationship among earthworms, soil and plant properties is beneficial for understanding the ecological functions of earthworms. Different densities of earthworms (high density, HDE; medium density, MDE; low density, LDE; control, CK) in soil columns were studied to reveal how earthworms influence soil physical and chemical properties and clover plant growth. The results showed that earthworms increased the large and medium aggregate content and decreased the microaggregate content. Soil aggregates in MDE were the most stable. Both the mean mass diameter (MWD) and geometric mean diameter of soil aggregates increased with the densities of earthworms. The average contents of soil organic carbon (SOC) in large-, medium-, and micro-aggregates were 5.5, 4.2, and $4.2 \mathrm{~g} \mathrm{~kg}-1$ in the treatments with earthworms. There was a significant correlation between SOC content and macroaggregate organic carbon content. The root characteristic values of earthworm-treated clover were significantly higher than those of the control. The clover root indexes were positively correlated with the SOC content and soil aggregates. We considered that earthworms altered the soil aggregate contents and promoted soil organic carbon storage, and thus promote the development of vegetation roots. This study provides scientific supports for a deeper understanding of the mechanism of earthworms on soil carbon storage.
\end{abstract}

\section{Hosted file}

manuscript20220124.docx available at https://authorea.com/users/459656/articles/555862effects-of-earthworm-metaphire-guillelmi-addition-on-soil-aggregate-organic-carboncontent-and-clover-root-characteristics 

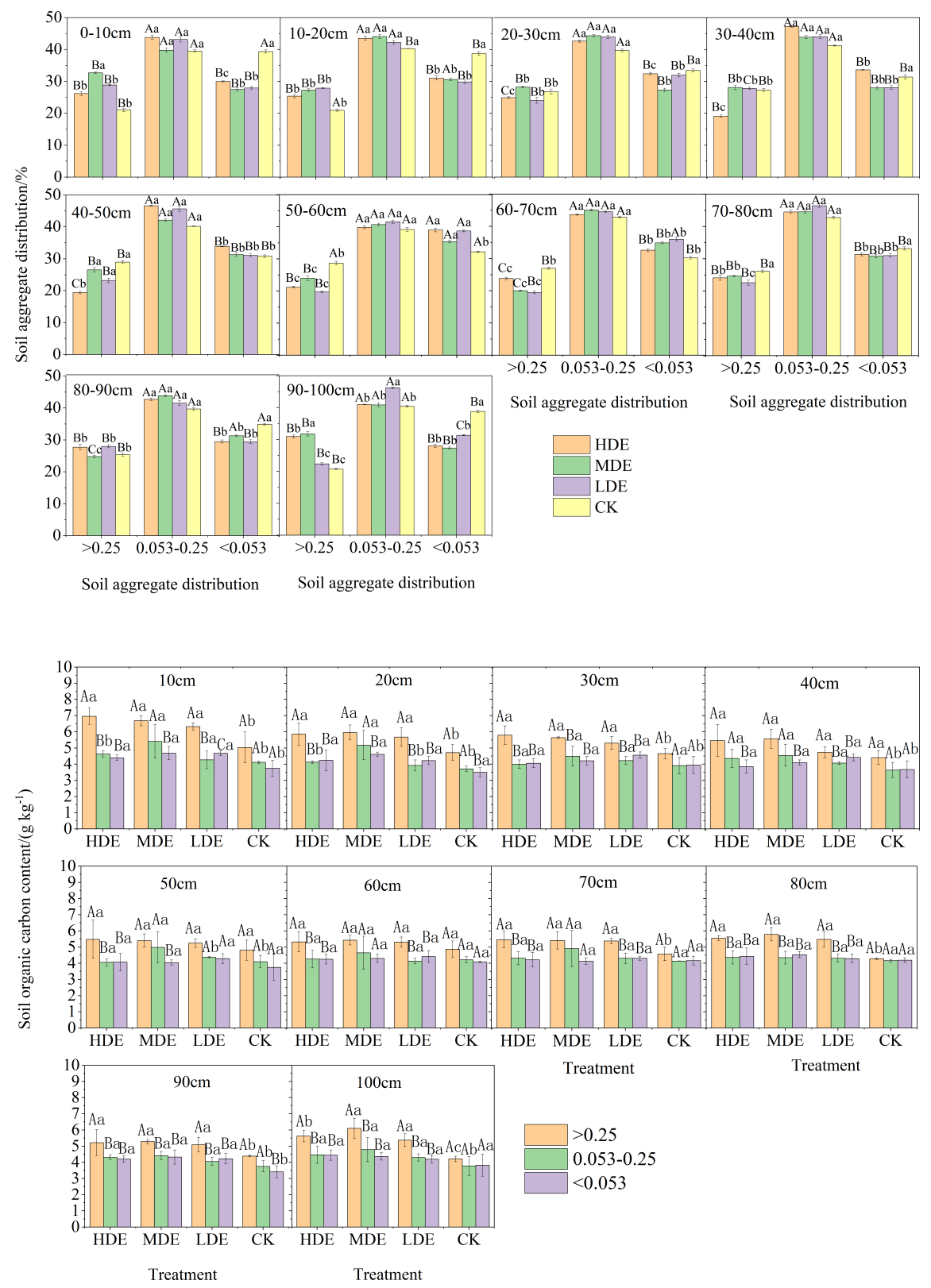

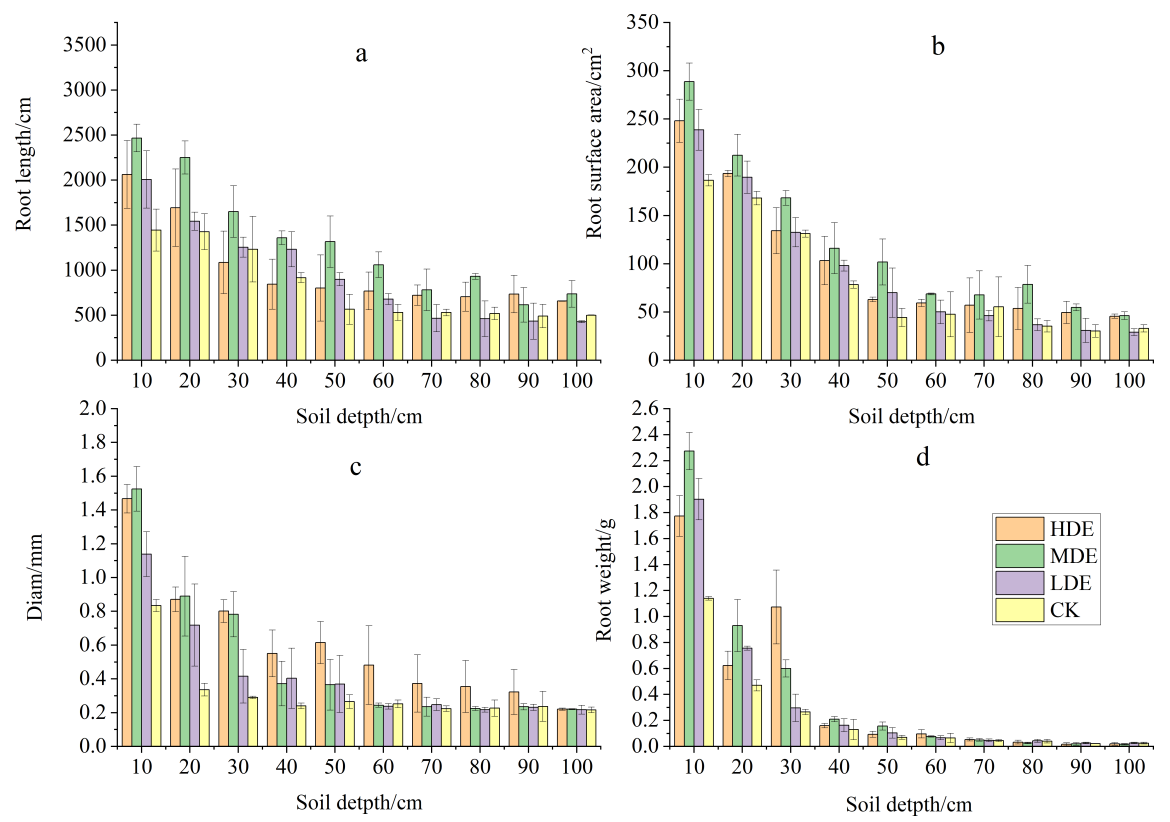